\title{
Journal of Nutrition, Health \& Aging: Summary of Recent Work and Future Directions
}

\author{
P. de Souto Barreto ${ }^{1,2}$, J.G. Ruiz ${ }^{3,4}$, R.A.Merchant ${ }^{5,6}$
}

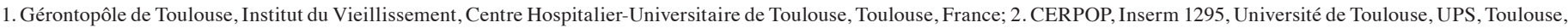

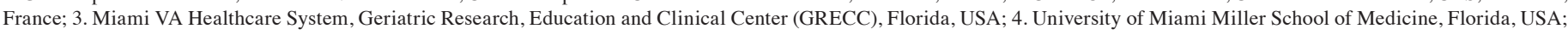

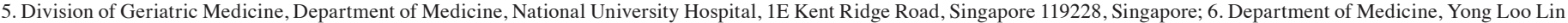
School of Medicine, National University of Singapore, Singapore

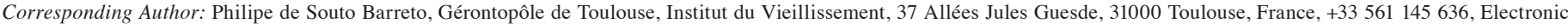
address: philipebarreto81@yahoo.com.br

$O$ ince its inception more than 20 years ago, the Journal of Nutrition, Health \& Aging (JNHA) has consistently published outstanding research in the fields of aging, population health, longevity and geriatrics. During its prestigious history, the JNHA has grown rapidly to become the outlet of choice for publication of research topics related to prevention and interventions to enable healthy aging, and delay or prevent the onset of disability associated with aging (1-3). Under the eminent leadership of Professor John E. Morley (2018-2021), the Journal significantly increased its number of published papers and citations, reaching an average of approximately 200 publications per year and over 570,000 articles' downloads and visits (data from 2021). The papers - included expert consensus and clinical guidelines (4-6) - represented major scholarly contributions to the field of aging. Under the capable direction of Professor Morley, the journal has striven to gain a better understanding of the clinical implications of the COVID-19 pandemic for older adults. Over 60 Journal's publications, many featuring renowned geriatrics experts, have proposed insightful perspectives and practical solutions to combat the burdens associated with the pandemic, such as social isolation and containment (7-12).

The JNHA is transitioning into a new leadership team. As the newly appointed co-Editors-in-Chief, we warmly congratulate Professor Morley for his impressive tenure as the former Editor-in-Chief of the JNHA. It is our great honor and privilege to serve as the new co-Editors-in-Chief of this influential world-renowned journal. It is indeed a great challenge but we look forward to carrying on and building on the great legacy of Professor Morley. In keeping with this tradition, we commit to further maintain and disseminate the Journal's highest standards of scientific quality and editorial excellence.

However, the unfolding of the new era presents us with the challenges of reconciling past journal activities with the need to introduce innovative features. As Editors-in-Chief, we will continue to emphasize the publication of research manuscripts that demonstrate the potential to change clinical practice on nutrition, lifestyle changes which promotes healthy aging as well as other aging-related topics. In terms of innovation, we highly encourage the submission of interventional studies, particularly randomized controlled clinical trials, that evaluate the effects of pharmacological and non-pharmacological interventions on aging-related clinical outcomes. Another research area we endeavor to prioritize is the emerging field of Geroscience (13-15), which is based on the hypothesis that by intervening on the basic mechanisms of biological aging, it is possible to prevent or delay the onset of a large number of chronic diseases and disabling conditions (16). We welcome submissions of animal model studies that identify new molecules, biomarkers and mechanistic pathways involved in the aging process, which demonstrate potential for the translation to clinical practice; clinical trials (from phase 1 to phase 3 ) that evaluate the effects of geroprotectors on biological aging and clinical outcomes; studies that investigate the effects of non-pharmacological interventions including lifestyle change (e.g., exercise, nutrition, caloric restriction, and multidomain interventions); and studies that investigate innovative models of care for vulnerable older adults such as the Integrated Care for Older People (ICOPE). Keeping these priorities in mind, we are still open to continue accepting submissions of research articles with diverse designs including longitudinal observational, casecontrol, and qualitative studies.

We are particularly interested in receiving manuscripts that examine the potential of models of care to improve clinical outcomes for vulnerable older adults in the short-to-medium term. Studies on the implementation of the ICOPE program will deserve special consideration (17). The World Health Organization (WHO) endorses the ICOPE program and encourages relevant research into its foundational components within an overall conceptual framework of healthy aging (1820). ICOPE represents a paradigmatic shift in the approach to the care of older adults from a disease-centered model to a more holistic, person- and function-centered approach. This healthcare program is designed to maintain older individuals' capacity, with the ultimate goal of preventing, delaying the onset and reducing the severity of functional dependence. ICOPE is based on the concept of intrinsic capacity, the composite of all physical and mental capacities (eg, locomotion, cognition, sensory) and their dynamic interactions with the environment which ultimately determine healthy aging.

As this new era in the JNHA trajectory begins, we are humbled by this new responsibility but at the same time excited at the prospect of advancing aging research that benefits our older adults worldwide. 
Conflicts of interest: P. de Souto Barreto and R.A. Merchant: no conflict of interest. J.G. Ruiz: Pfizer consulting.

\section{References}

1. Merchant RA, Tsoi CT, Tan WM, Lau W, Sandrasageran S, Arai H. Community-Based Peer-Led Intervention for Healthy Ageing and Evaluation of the «HAPPY » Program. J Nutr Health Aging. 2021;25(4):520-7. doi: 10.1007/s12603-021-1606-6

2. Mendes J, Afonso C, Borges N, Santos A, Moreira P, Padrão P, et al. Adherence to a Mediterranean Dietary Pattern and Functional Parameters: A Cross-Sectional Study in an Older Population. J Nutr Health Aging. 2020;24(2):138-46. doi: 10.1007/s12603019-1300-0.

3. Hsu K-J, Chien K-Y, Tsai S-C, Tsai Y-S, Liao Y-H, Chen J-J, et al. Effects of Exercise Alone or in Combination with High-Protein Diet on Muscle Function, Aerobic Capacity, and Physical Function in Middle-Aged Obese Adults: A Randomized Controlled Trial. J Nutr Health Aging. 2021;25(6):727-34. doi: 10.1007/s12603-0211599-1

4. Izquierdo M, Merchant RA, Morley JE, Anker SD, Aprahamian I, Arai H, et al. International Exercise Recommendations in Older Adults (ICFSR): Expert Consensus Guidelines. J Nutr Health Aging. 2021;25(7):824-53. doi: 10.1007/s12603-021-1665-8

5. Ruiz JG, Dent E, Morley JE, Merchant RA, Beilby J, Beard J, et al. Screening for and Managing the Person with Frailty in Primary Care: ICFSR Consensus Guidelines. J Nutr Health Aging. 2020;24(9):920-7. doi: 10.1007/s12603-020-1492-3

6. Dent E, Morley JE, Cruz-Jentoft AJ, Woodhouse L, Rodríguez-Mañas L, Fried LP, et al. Physical Frailty: ICFSR International Clinical Practice Guidelines for Identification and Management. J Nutr Health Aging. 2019;23(9):771-87. doi: 10.1007/s12603-019$1273-\mathrm{z}$

7. Sepúlveda-Loyola W, Rodríguez-Sánchez I, Pérez-Rodríguez P, Ganz F, Torralba R, Oliveira DV, et al. Impact of Social Isolation Due to COVID-19 on Health in Older People: Mental and Physical Effects and Recommendations. J Nutr Health Aging. 2020;24(9):938-47. doi: 10.1007/s12603-020-1469-2

8. Dai S-P, Zhao X, Wu J-H. Effects of Comorbidities on the Elderly Patients with COVID-19: Clinical Characteristics of Elderly Patients Infected with COVID-19 from Sichuan, China. J Nutr Health Aging. 2021;25(1):18-24. doi: 10.1007/s12603-0201486-1
9. Yu Y, Ye J, Chen M, Jiang C, Lin W, Lu Y, et al. Malnutrition Prolongs the Hospitalization of Patients with COVID-19 Infection: A Clinical Epidemiological Analysis. J Nutr Health Aging. 2021;25(3):369-73. doi: 10.1007/s12603-020-1541-y

10. Li Q, Hu P, Kang H, Zhou F. Clinical Characteristics and Short-Term Outcomes of Acute Kidney Injury Missed Diagnosis in Older Patients with Severe COVID-19 in Intensive Care Unit. J Nutr Health Aging. 2021;25(4):492-500. doi: 10.1007/s12603020-1550-X

11. Yang Y, Luo K, Jiang Y, Yu Q, Huang X, Wang J, et al. The Impact of Frailty on COVID-19 Outcomes: A Systematic Review and Meta-analysis of 16 Cohort Studies. J Nutr Health Aging. 2021;25(5):702-9. doi: 10.1007/s12603-021-1611-9

12. Rolland Y, Cesari M, Morley JE, Merchant R, Vellas B. Editorial: COVID19 Vaccination in Frail People. Lots of Hope and Some Questions. J Nutr Health Aging. 2021;25(2):146-7. doi: 10.1007/s12603-021-1591-9

13. Sierra F, Kohanski R. Geroscience and the trans-NIH Geroscience Interest Group, GSIG. GeroScience. 2017;39(1):1-5. doi: 10.1007/s11357-016-9954-6

14. Kennedy BK, Berger SL, Brunet A, Campisi J, Cuervo AM, Epel ES, et al Geroscience: linking aging to chronic disease. Cell. 6 nov 2014;159(4):709-13. doi: 10.1016/j.cell.2014.10.039

15. Sierra F. Moving Geroscience Into Uncharted Waters. J Gerontol A Biol Sci Med Sci. 2016;71(11):1385-7. doi: 10.1093/gerona/glw087

16. López-Otín C, Blasco MA, Partridge L, Serrano M, Kroemer G. The hallmarks of aging. Cell. 6 juin 2013;153(6):1194-217. doi: 10.1016/j.cell.2013.05.039

17. WHO । Guidance on person-centred assessment and pathways in primary care [Internet]. WHO. Available at: https://www.who.int/publications/i/item/WHO-FWCALC-19.1

18. World Health Organization. World report on ageing and health. [Internet]. WHO Press; 2015. Available at: https://www.who.int/ageing/events/world-report-2015launch/en/

19. Cesari M, Araujo de Carvalho I, Amuthavalli Thiyagarajan J, Cooper C, Martin FC, Reginster J-Y, et al. Evidence for the Domains Supporting the Construct of Intrinsic Capacity. J Gerontol A Biol Sci Med Sci. 10 2018;73(12):1653-60. doi: 10.1093/ gerona/gly011

20. Gonzalez-Bautista E, Andrieu S, Gutiérrez-Robledo LM, García-Chanes RE, de Souto Barreto P. In the quest of a Standard Index of Intrinsic Capacity. A Critical Literature Review. J Nutr Health Aging. 2020;24(9):959-65. doi: 10.1007/s12603-020-1394-4

How to cite this article: P. de Souto Barreto, J.G. Ruiz, R.A. Merchant. Journal of Nutrition, Health \& Aging: Summary of Recent Work and Future Directions. J Nutr Health Aging. 2022;26(1):1-2, http://dx.doi.org/10.1007/s12603-022-1725-8 